\title{
ANALISIS HUBUNGAN STATUS GIZI DAN IKLIM KERJA DENGAN KELELAHAN KERJA DI CATERING HIKMAH FOOD SURABAYA
}

\author{
Ridha Ramayanti \\ Departemen Keselamatan dan Kesehatan Kerja \\ Fakultas Kesehatan Masyarakat Universitas Airlangga \\ E-mail: ridharamayanti@gmail.com
}

\begin{abstract}
Work fatigue is condition which some factors have interaction with the workers. Fatigue may occur in the workforce by various factors, such as nutritional status and work climate. This study was conducted to analyze the relationship between nutritional status and work climate with work fatigue in Hikmah Food Catering. This was an observational analytic study using a cross sectional design. Samples size 43 peoples were taken by simple random sampling method. The correlation between the dependent and independent variables were analyzed by spearman correlation test $(\alpha=0,05)$. Work climate in this catering were kitchen area $29,6^{\circ} \mathrm{C}$, non $\mathrm{AC} 26,5^{\circ} \mathrm{C}$ area, and air-conditioned area $20,3^{\circ} \mathrm{C}$. Spearman correlation test results showed that there was nutritional status which had no significant association with work fatigue $(p=0,954)$ and there was work climate which had a significant association with work fatigue $(p=0.004)$. The conclusion of this research is nutritional status has no relation with fatigue, meanwhile work climate have a relation with work fatigue. There are advised for the industry such as providing sufficient drinking water supplies, and installing push pull system ventilation, especially in the kitchen area.
\end{abstract}

Keywords: worker, nutritional status, work climate, work fatigue, catering

\begin{abstract}
ABSTRAK
Kelelahan kerja adalah sebuah kondisi yang erat kaitannya dengan tenaga kerja. Kelelahan dapat terjadi pada tenaga kerja karena berbagai faktor antara lain status gizi dan iklim kerja. Penelitian ini dilakukan untuk menganalisis hubungan antara status gizi dan iklim kerja dengan kelelahan kerja di catering Hikmah Food Surabaya. Penelitian ini merupakan penelitian observasional analitik dengan desain cross sectional. Sampel penelitian sebesar 43 orang diambil dengan metode simple random sampling. Korelasi antara variabel dependen dan independen dianalisis dengan uji korelasi spearman $(\alpha=0,05)$. Iklim kerja di catering ini yaitu area dapur $29,6^{\circ} \mathrm{C}$, area non $\mathrm{AC} 26,5^{\circ} \mathrm{C}$, dan area ber-AC $20,3^{\circ} \mathrm{C}$. Hasil uji korelasi spearman menunjukkan bahwa tidak ada hubungan signifikan antara status gizi dengan kelelahan kerja $(\mathrm{p}=0.954)$ dan ada hubungan yang signifikan antara iklim kerja dengan kelelahan kerja $(p=0,004)$. Kesimpulan dari penelitian ini adalah status gizi tidak berhubungan dengan kelelahan kerja, sementara iklim kerja berhubungan dengan kelelahan kerja. Saran untuk perusahaan agar menyediakan pasokan air minum yang cukup dan memasang ventilasi sistem dorong tarik, terutama di area dapur.
\end{abstract}

Kata kunci: tenaga kerja, status gizi, iklim kerja, kelelahan kerja, catering

\section{PENDAHULUAN}

Kelelahan merupakan bagian dari permasalahan umum yang sering dijumpai pada tenaga kerja. Menurut beberapa peneliti, kelelahan secara nyata dapat mempengaruhi kesehatan tenaga kerja dan dapat menurunkan produktivitas. Budiono (2003), menyatakan kelelahan kerja ditandai dengan melemahnya tenaga kerja dalam melakukan pekerjaan atau kegiatan, sehingga akan meningkatkan kesalahan dalam melakukan pekerjaan dan akibat fatalnya adalah terjadinya kecelakaan kerja.
Hasil studi Departemen Kesehatan RI mengenai Pembiayaan Jaminan Kesehatan bagi Pekerja Sektor Informal pada tahun 2006 di 8 provinsi menunjukkan adanya keluhan terbanyak yaitu kelelahan dengan gejala pegal-pegal sebesar $67 \%$. Hasil survei di USA menghasilkan 24\% seluruh orang dewasa yang datang ke poliklinik menderita kelelahan. Faktor yang menyebabkan terjadinya kelelahan adalah kesegaran jasmani, kebiasaan merokok, masalah psikologis, status kesehatan, jenis kelamin, status gizi, waktu kerja, beban kerja, usia, dan masalah lingkungan kerja (Tarwaka, 2004). 
Pendapat dari Tarwaka (2004) bahwa status gizi merupakan penyebab terjadinya kelelahan kerja diperkuat oleh hasil riset dari Oentoro (2004) yang menunjukkan secara klinis terdapat hubungan antara status gizi seseorang dengan performa tubuh secara keseluruhan. Orang yang berada dalam kondisi gizi yang kurang baik dalam arti intake makanan dalam tubuh kurang dari normal maka akan lebih mudah mengalami kelelahan dalam melakukan pekerjaan. Selain status gizi juga terdapat penyebab lain yang mempengaruhi kelelahan kerja yaitu iklim kerja. Iklim kerja adalah hasil perpaduan antara suhu, kelembaban, kecepatan gerakan udara dan panas radiasi dengan tingkat pengeluaran panas dari tubuh tenaga kerja sebagai akibat pekerjaannya, yang dimaksudkan dalam peraturan ini adalah iklim kerja panas (Permenakertrans RI No 13 Tahun 2011). Penelitian yang dilakukan oleh Wahyuni pada pekerja bagian instalasi laundry rumah sakit menunjukkan bahwa 23 pekerja yang bekerja pada suhu ruangan yang tinggi (diatas $28^{\circ} \mathrm{C}$ ), $95,7 \%$ diantaranya mengalami kelelahan kerja.

Tenaga kerja catering Hikmah Food berada pada klasifikasi status gizi yang berbeda yang berpengaruh terhadap kinerja. Selain itu, iklim kerja juga memicu terjadinya kelelahan kerja tenaga kerja catering Hikmah Food Surabaya. Beberapa tenaga kerja harus bertahan di dalam dapur yang tergolong iklim kerja tinggi karena pajanan panas kompor, sedangkan beberapa tenaga kerja bekerja dalam ruangan yang tergolong normal. Kelelahan kerja sebagai salah satu sumber masalah bagi keselamatan dan kesehatan pekerja, tentu saja tidak dapat dibiarkan begitu saja, karena tenaga kerja merupakan aset perusahaan yang dapat mempengaruhi produktivitas perusahaan. Berdasarkan beberapa hal tersebut maka perlu dilakukan upaya untuk mengurangi kelelahan kerja salah satunya adalah dengan memperhatikan status gizi dan iklim kerja di dalam perusahaan. Tujuan penelitian ini adalah menganalisis hubungan status gizi dan iklim kerja terhadap kelelahan kerja tenaga kerja catering Hikmah Food Surabaya.

\section{METODE}

Penelitian yang dilakukan merupakan penelitian observasional analitik dengan menggunakan metode cross sectional. Populasi penelitian dalam penelitian ini adalah tenaga kerja tetap catering Hikmah Food Surabaya sebanyak 48 tenaga kerja. Sampel yang diambil adalah sebagian dari tenaga kerja yang diambil dengan menggunakan rumus simple random sampling sehingga didapatkan sampel yang akan diteliti adalah 43 tenaga kerja. Penelitian ini dilakukan di catering Hikmah Food Surabaya yang berlokasi di Jl. Gayung Kebonsari Tengah 13 Kompleks SD Al-Hikmah Surabaya. Waktu pengumpulan data yaitu pada Februari 2015.

Teknik pengumpulan data dilaksanakan dengan mengambil data primer dan data sekunder. Data primer meliputi kuesioner kelelahan kerja, pengukuran berat badan dan tinggi badan, serta pengukuran iklim kerja. Data sekunder meliputi usia, tingkat pendidikan dan jenis kelamin.

\section{HASIL}

\section{Karakteristik Responden}

Karakteristik responden meliputi: usia, jenis kelamin, dan tingkat pendidikan. Berdasarkan hasil penelitian dapat diketahui bahwa sebagian besar pekerja tergolong pada usia 31-35 tahun $(30,2 \%)$ yaitu sebesar 13 orang, jenis kelamin lakilaki $(76,7 \%)$ yaitu sebesar 33 orang, dan tingkat pendidikan SMA $(67,4 \%)$ yaitu sebesar 29 orang.

\section{Distribusi Status Gizi Responden}

Status gizi diperoleh dari perhitungan indeks massa tubuh (IMT). Status gizi responden dibagi menjadi 3 kategori, yaitu kurus dengan IMT $<18,4$, normal dengan IMT 18,5-25, dan gemuk dengan IMT $>25$. Distribusi responden menurut status gizi dari dapat dilihat pada Tabel 1 sebagai berikut:

Tabel 1. Distribusi Responden Berdasarkan Status Gizi pada Tenaga Kerja Catering Hikmah Food Surabaya

\begin{tabular}{lcc}
\hline \multicolumn{1}{c}{ Status Gizi } & Frekuensi (n) & Persentase (\%) \\
\hline Kurus & 3 & 6,9 \\
Normal & 19 & 44,1 \\
Gemuk & 21 & 48,8 \\
\hline Total & 43 & 100,00 \\
\hline
\end{tabular}

Berdasarkan Tabel 2 ditunjukkan bahwa sebagian besar responden mempunyai status gizi gemuk, yaitu berjumlah 21 responden $(48,8 \%)$ dan sebagian besar status gizi gemuk pada tenaga kerja terdapat pada area non AC, yaitu sebesar $47,6 \%$.

\section{Distribusi Iklim Kerja Responden}

Pengukuran iklim kerja di Catering Hikmah Food Surabaya dengan menggunakan alat digital questemp 36. Pengukuran iklim kerja meliputi 
pengukuran suhu kering (SK), suhu basah (SB), suhu bola (SG), dan indeks suhu basah (ISBB). Berikut ini hasil pengukuran iklim kerja di tempat responden melakukan pekerjaan.

Tabel 2. Hasil Pengukuran Iklim Kerja di Catering Hikmah Food Surabaya

\begin{tabular}{lcllll}
\hline \multirow{2}{*}{ Lokasi } & \multirow{2}{*}{ Jam } & $\begin{array}{c}\text { SK } \\
\left({ }^{\circ} \mathbf{C}\right)\end{array}$ & $\begin{array}{c}\text { SB } \\
\left({ }^{\circ} \mathbf{C}\right)\end{array}$ & $\begin{array}{c}\text { SG } \\
\left({ }^{\circ} \mathbf{C}\right)\end{array}$ & $\begin{array}{c}\text { ISBB } \\
\left({ }^{\circ} \mathbf{C}\right)\end{array}$ \\
\hline \multirow{2}{*}{ Area } & 07.00 & 23,2 & 17,3 & 23,5 & 19,1 \\
Ber AC & 11.05 & 23,9 & 22,3 & 24,5 & 22,9 \\
& 15.00 & 21,9 & 17,6 & 22,5 & 19,1 \\
\hline Rata-rata & & $\mathbf{2 3}$ & $\mathbf{1 9 , 0 6}$ & $\mathbf{2 3 , 5}$ & $\mathbf{2 0 , 3}$ \\
\hline Area Non & 07.30 & 26,7 & 25,4 & 28 & 26,2 \\
AC & 11.40 & 28,1 & 24,8 & 28,5 & 25,9 \\
& 15.35 & 27,6 & 27 & 28,2 & 27,4 \\
\hline Rata-rata & & $\mathbf{2 7 , 4}$ & $\mathbf{2 5 , 7}$ & $\mathbf{2 8 , 2}$ & $\mathbf{2 6 , 5}$ \\
\hline \multirow{2}{*}{ Area Dapur } & 08.00 & 33,4 & 29,7 & 34,5 & 31 \\
& 12.30 & 32,7 & 28 & 33,4 & 29,6 \\
& 16.10 & 31,2 & 26,7 & 31,9 & 28,3 \\
\hline Rata-rata & & 32,4 & 28,1 & 33,2 & 29,6 \\
\hline
\end{tabular}

Berdasarkan hasil pengukuran pada Tabel 2 suhu kering (SK), suhu tertinggi terdapat pada area dapur, yaitu sebesar $32,4^{\circ} \mathrm{C}$ dan suhu terendah pada area ber-AC, yaitu $23^{\circ} \mathrm{C}$. Hasil pengukuran suhu basah (SB) didapatkan hasil tertinggi pada area dapur, yaitu sebesar $28,1^{\circ} \mathrm{C}$ sedangkan suhu terendah pada area ber-AC, yaitu sebesar $19,06^{\circ} \mathrm{C}$. Hasil pengukuran suhu bola basah (SG) didapatkan hasil tertinggi pada area dapur, yaitu sebesar $33.2^{\circ} \mathrm{C}$ sedangkan hasil terendah didapatkan pada area ber$\mathrm{AC}$, yaitu sebesar $23,5^{\circ} \mathrm{C}$. Hasil pengukuran Indeks Suhu Basah (ISBB), didapatkan hasil tertinggi pada area dapur, yaitu sebesar $29,6^{\circ} \mathrm{C}$ sedangkan hasil terendah terdapat pada area ber-AC, yaitu sebesar $20,3^{\circ} \mathrm{C}$.

Untuk menentukan iklim kerja tersebut sesuai atau tidak dengan Nilai Ambang Batas (NAB) maka hasil pengukuran iklim harus disesuaikan dengan beban kerja. Hasil tersebut akan dibandingkan dengan Peraturan Menteri Tenaga Kerja Nomor 13 Tahun 2011 maka iklim kerja responden dibagi menjadi 2 kategori, yaitu $\leq \mathrm{NAB}$ dan $>\mathrm{NAB}$. Distribusi responden menurut iklim kerja dapat dilihat pada Tabel 3 .

Tabel 3 menunjukkan bahwa sebagian besar responden bekerja dengan iklim kerja $\leq \mathrm{NAB}$, yaitu berjumlah 36 responden $(83,7 \%)$ dan sebagian besar tenaga kerja dengan iklim kerja $\leq \mathrm{NAB}$ terdapat pada area kerja non AC, yaitu sebesar $61,1 \%$. Sedangkan iklim kerja $>$ NAB yang dialami tenaga
Tabel 3. Distribusi Responden Berdasarkan Iklim Kerja pada Tenaga Kerja Catering Hikmah Food Surabaya

\begin{tabular}{lcc}
\hline Iklim Kerja & Frekuensi (n) & Persentase (\%) \\
\hline$\leq$ NAB & 36 & 83,70 \\
>NAB & 7 & 16,20 \\
\hline Total & 43 & 100,00 \\
\hline
\end{tabular}

kerja sebagian besar terdapat pada area dapur, yaitu sebesar $85,7 \%$.

\section{Distribusi Kelelahan Kerja Responden}

Kelelahan kerja merupakan salah satu penyebab terjadinya kecelakaan dan penurunan produktivitas. Pengukuran kelelahan kerja dilakukan dengan menggunakan kuesioner Industrial Fatigue Research Committee (IFRC). Klasifikasi kelelahan kerja berdasarkan skor terdiri dari kelelahan kerja rendah (30-52), kelelahan kerja sedang (53-75), kelelahan kerja tinggi (76-98), dan kelelahan kerja sangat tinggi (99-120). Berikut ini merupakan distribusi kelelahan di Catering Hikmah Food Surabaya.

Tabel 4. Distribusi Responden Berdasarkan Kelelahan Kerja pada Tenaga Kerja Catering Hikmah Food Surabaya

\begin{tabular}{lcc}
\hline Kelelahan Kerja & Frekuensi (n) & Persentase (\%) \\
\hline Rendah & 15 & 34,80 \\
Sedang & 24 & 55,80 \\
Tinggi & 4 & 9,30 \\
\hline Total & 43 & 100,00 \\
\hline
\end{tabular}

Hasil pengukuran kelelahan kerja menunjukkan bahwa tingkat kelelahan tenaga kerja sebagian besar berada pada tingkat kelelahan sedang sebanyak 24 responden $(55,8 \%)$. Selain itu terdapat responden yang mempunyai kelelahan kerja tinggi, yaitu berjumlah 4 responden $(9,3 \%)$. Tenaga kerja dengan tingkat kelelahan sedang sebagian besar terdapat pada area non AC, yaitu sebesar $75 \%$. Kelelahan kerja tinggi yang dialami tenaga kerja sebagian besar terdapat pada area dapur, yaitu sebesar $75 \%$.

\section{Hubungan Antara Status Gizi dengan Kelelahan Kerja}

Berdasarkan data penelitian status gizi dibagi menjadi 3 kategori yaitu kategori kurus (IMT = $<18,4)$, normal $(\mathrm{IMT}=18,5-25,0)$, dan gemuk $(\mathrm{IMT}=25,1->27,0)$. Berikut ini adalah hasil tabulasi silang antara status gizi dengan kelelahan kerja. 
Tabel 5. Persentase Kelelahan Kerja Berdasarkan Status Gizi di Catering Hikmah Food Surabaya

\begin{tabular}{lcccccccc}
\hline \multirow{2}{*}{$\begin{array}{c}\text { Status } \\
\text { Gizi }\end{array}$} & \multicolumn{9}{c}{ Kelelahan Kerja } & \multirow{2}{*}{ Total } \\
\cline { 2 - 8 } & \multicolumn{1}{c}{ Rendah } & \multicolumn{2}{c}{ Sedang } & \multicolumn{2}{c}{ Tinggi } & \\
\cline { 2 - 8 } & $\mathbf{n}$ & $\mathbf{\%}$ & $\mathbf{n}$ & $\mathbf{\%}$ & $\mathbf{n}$ & $\mathbf{\%}$ & $\mathbf{N}$ & $\mathbf{\%}$ \\
\hline Kurus & 1 & 33,3 & 2 & 66,6 & 0 & 0 & 3 & 100 \\
Normal & 5 & 26,3 & 14 & 73,6 & 0 & 0 & 19 & 100 \\
\hline Gemuk & 9 & 42,8 & 8 & 38,08 & 4 & 19,04 & 21 & 100 \\
\hline
\end{tabular}

Berdasarkan hasil penelitian pada 43 responden diperoleh hasil bahwa sebagian besar tenaga kerja dengan status gizi normal mengalami kelelahan kerja kategori sedang, yaitu sebesar 73,6\%.

Menurut perhitungan statistika tidak terdapat hubungan yang bermakna antara status gizi dengan kelelahan kerja dengan nilai $p=0,954>\alpha=0,05$.

\section{Hubungan Antara Iklim Kerja dengan Kelelahan Kerja}

Hasil penelitian iklim kerja dibagi menjadi 2 jenis yaitu $\leq$ NAB (jika beban kerja ringan ISBB $\leq 30,6^{\circ} \mathrm{C}$; beban kerja sedang ISBB $\leq 28^{\circ} \mathrm{C}$ ) dan $>\mathrm{NAB}$ (jika beban kerja ringan ISBB $>30,6^{\circ} \mathrm{C}$; beban kerja sedang ISBB $>28^{\circ} \mathrm{C}$; serta beban kerja berat pada semua kondisi ISBB). Berikut ini adalah hasil tabulasi silang antara iklim kerja dengan kelelahan kerja.

Tabel 6. Persentase Kelelahan Kerja Berdasarkan Iklim Kerja di Catering Hikmah Food Surabaya

\begin{tabular}{|c|c|c|c|c|c|c|c|c|}
\hline \multirow{3}{*}{$\begin{array}{l}\text { Iklim } \\
\text { Kerja }\end{array}$} & \multicolumn{6}{|c|}{ Kelelahan Kerja } & \multirow{2}{*}{\multicolumn{2}{|c|}{ Total }} \\
\hline & \multicolumn{2}{|c|}{ Rendah } & \multicolumn{2}{|c|}{ Sedang } & \multicolumn{2}{|c|}{ Tinggi } & & \\
\hline & n & $\%$ & $\mathbf{n}$ & $\%$ & n & $\%$ & n & $\%$ \\
\hline$\leq \mathrm{NAl}$ & 14 & 38,8 & 22 & 61,1 & 0 & 0 & 36 & 100 \\
\hline$>$ NAB & 1 & 14,2 & 2 & 28,5 & 4 & 57,1 & 7 & 100 \\
\hline Total & 9 & 20,9 & 23 & 53,4 & 11 & 25,5 & 43 & 100 \\
\hline
\end{tabular}

Berdasarkan Tabel 6 dapat diketahui bahwa pada kondisi iklim kerja melebihi ambang batas pada kategori beban kerja yang telah ditentukan terdapat $57,1 \%$ yang mengalami kelelahan kerja kategori tinggi.

Menurut perhitungan statistik antara iklim kerja dengan kelelahan kerja memiliki hubungan yang bermakna dengan nilai $p=0,004<\alpha=0,05$. Koefisien korelasi antara dua variabel tersebut menurut perhitungan secara statistik adalah sebesar 0,430 yang berarti memiliki hubungan yang sedang.

\section{PEMBAHASAN}

\section{Karakteristik Responden}

Beberapa karakteristik responden yang dibahas dalam penelitian ini antara lain: usia, jenis kelamin, dan tingkat pendidikan. Penentuan sampel untuk responden dalam penelitian ini menggunakan kriteria inklusi dan eksklusi. Tujuan inklusi dan eksklusi dibuat untuk menghindari adanya bisa dalam penelitian. Kriteria tersebut dibuat berdasarkan teori dan penelitian yang ada serta kondisi di tempat penelitian.

Berdasarkan hasil penelitian pada 43 responden di Catering Hikmah Food Surabaya diketahui bahwa usia responden berkisar antara 20-51 tahun dan sebagian besar responden berusia 31-35 tahun sebanyak 13 responden. Usia tersebut merupakan usia produktif manusia yang mempengaruhi kondisi, kemampuan, dan kapasitas tubuh dalam melakukan aktivitas sehari-hari. Hal ini sesuai dengan pendapat dari Tarwaka (2010) bahwa usia seseorang berbanding langsung dengan kapasitas fisik sampai batas waktu tertentu dan mencapai puncaknya pada usia 25 tahun. Pada usia 50-60 tahun kekuatan otot menurun sebesar $25 \%$, kemampuan sensoris-motoris menurun sebanyak $60 \%$.

Bertambahnya usia akan diikuti penurunan $\mathrm{VO}^{2}$ max, tajam penglihatan, pendengaran, kecepatan membedakan sesuatu, membuat keputusan dan mengingat jangka pendek. Perubahan fisiologis di dalam tubuh dapat menyebabkan responden tidak dapat bekerja dengan beban fisik yang berat sehingga dapat menyebabkan terjadinya kelelahan kerja. Dengan demikian, pengaruh usia harus selalu dijadikan pertimbangan dalam memberikan pekerjaan kepada seseorang (Tarwaka, 2010).

Hasil penelitian pada 43 responden di Catering Hikmah Food Surabaya menunjukkan bahwa sebagian besar tenaga kerja berjenis kelamin lakilaki. Pekerjaan di Catering Hikmah Food Surabaya terdiri dari pekerjaan yang dominan membutuhkan fisik tepatnya pada pekerja dapur dan pekerjaan yang dominan membutuhkan inisiatif tinggi seperti pada pekerja di bagian kantor. Namun pekerjaan dengan dominan membutuhkan fisik adalah pekerjaan dengan jumlah tenaga kerja paling banyak karena produksi dari Catering Hikmah Food Surabaya adalah penyediaan makanan secara massal. Hal tersebut menyebabkan pekerjaan didominasi dengan pekerjaan yang membutuhkan kekuatan fisik sehingga lebih banyak tenaga kerja dari Catering Hikmah Food Surabaya berjenis kelamin laki-laki. 
Hal tersebut sesuai dengan pendapat dari Suma'mur (2009), bahwa laki-laki memiliki kemampuan fisik dan kekuatan kerja otot yang berbeda dengan wanita. Perbedaan tersebut dapat dilihat melalui ukuran tubuh dan kekuatan otot dari wanita relatif kurang jika dibandingkan dengan pria. Kemudian pada saat wanita sedang haid yang tidak normal (dysmenorrhoea), maka akan dirasakan sakit sehingga akan lebih cepat lelah. Dan juga pada beberapa pekerjaan di Catering Hikmah Food Surabaya berada pada suhu panas seperti pada proses memasak di dapur. Keseluruhan pekerja dapur berjenis kelamin laki-laki, hal ini sesuai dengan pendapat Tarwaka (2010), bahwa seorang wanita lebih tahan terhadap suhu dingin daripada suhu panas. Hal tersebut disebabkan karena tubuh seorang wanita mempunyai jaringan dengan daya konduksi yang lebih tinggi terhadap panas bila dibandingkan dengan laki-laki. Akibatnya pekerja wanita akan memberikan lebih banyak reaksi perifer bila bekerja pada cuaca panas dan memicu untuk lebih cepat terjadinya kelelahan.

Menurut Setyawati (2010), bahwa semakin tinggi pendidikan maka semakin mudah seseorang berpikir secara luas, makin tinggi daya inisiatif, dan makin mudah pula menemukan cara-cara yang efisien guna menyelesaikan pekerjaannya dengan baik. Berdasarkan hasil penelitian pada 43 responden menunjukkan bahwa sebagian besar tenaga kerja Catering Hikmah Food Surabaya mempunyai tingkat pendidikan SMA. Hal tersebut dikarenakan pada pekerjaan di Hikmah Food termasuk kategori pekerjaan yang tidak banyak membutuhkan penyusunan rencana, koordinasi ide, dan pemecahan masalah yang tinggi sehingga dengan tenaga kerja dengan tingkat pendidikan SMA sudah cukup untuk mampu menyelesaikan pekerjaan khususnya di bagian service dan bagian produksi.

\section{Status Gizi}

Indeks Massa Tubuh (IMT) merupakan alat atau cara yang sederhana untuk memantau status gizi orang dewasa, khususnya yang berkaitan dengan kekurangan dan kelebihan berat badan (WHO, 2011). Masalah kekurangan dan kelebihan gizi pada orang dewasa merupakan masalah penting karena selain mempunyai risiko penyakit-penyakit tertentu, juga dapat mempengaruhi produktivitas kerja (Supariasa, 2002). Hasil penelitian pada 43 responden di Catering Hikmah Food Surabaya menunjukkan bahwa dari keseluruhan tenaga kerja
Hikmah Food sebagian besar mempunyai status gizi gemuk. Selain itu dapat ditemukan bahwa tenaga kerja status gizi gemuk sebagian besar terdapat pada area non AC.

Namun, apabila ditinjau berdasarkan area kerja, pada area non AC lebih banyak tenaga kerja dengan status gizi normal. Sedangkan pada area ber-AC sebagian besar tenaga kerja mempunyai status gizi gemuk. Hal tersebut dikarenakan pada area ber-AC tenaga kerja cenderung bekerja dengan menggunakan komputer dan tidak memerlukan banyak gerakan sehingga tidak banyak menggunakan energi yang pada akhirnya dapat mempengaruhi status gizi tenaga kerja tersebut. Sedangkan pada area dapur dan non AC memiliki pekerjaan yang harus dilakukan secara aktif, dalam kondisi berdiri, dan memerlukan banyak pergerakan. Apabila dalam area dapur dan area non-AC terdapat tenaga kerja dengan status gizi gemuk, maka kemungkinan tenaga kerja tersebut telah mempunyai status gizi gemuk sebelum bekerja pada catering Hikmah Food.

Status kesehatan dan nutrisi atau keadaan gizi berhubungan erat satu sama lainnya dan berpengaruh pada produktivitas dan efisiensi kerja. Dalam melakukan pekerjaan tubuh memerlukan energi, apabila kekurangan baik secara kuantitatif maupun kualitatif kapasitas kerja akan terganggu (Tarwaka, 2010). Apabila konsumsi makanan seimbang dengan energi yang dikeluarkan maka status gizi akan baik. Namun, jika konsumsi makanan tidak seimbang dengan energi yang dikeluarkan maka seseorang akan mengalami kegemukan atau menjadi kurus sehingga akan mudah mengalami kelelahan. Sesuai pendapat Suma'mur (2009), bahwa gizi kurang atau lebih dapat mengakibatkan penyakit dan berkurangnya kemampuan kerja.

Maka upaya perbaikan status gizi bagi tenaga kerja perlu dilakukan salah satunya dengan melakukan pengaturan asupan makanan dan pelaksanaan kegiatan olahraga. Menurut Centre for Diseases Control and Prevention (CDC) pada tahun 2011, salah satu manfaat olahraga yaitu mengontrol berat badan. Lebih banyak aktivitas fisik yang dilakukan, lebih banyak kalori yang dibakar untuk digunakan sebagai energi dalam menurunkan berat badan (CDC, 2011). Maka dari itu olahraga dapat menjadi salah satu cara untuk mempertahankan berat badan ideal demi kesehatan tenaga kerja dan menjaga produktivitas kerja. Olahraga yang dapat dilakukan bersama-sama misalnya senam rutin satu minggu sekali yang diikuti oleh seluruh tenaga kerja di perusahaan. 


\section{Iklim Kerja}

Pengukuran iklim kerja dilakukan dengan menggunakan alat digital questemp 36 dengan parameter Indeks Suhu Basah dan Bola (ISBB). Pengukuran dilakukan di tiga area yaitu area dapur, area non AC, dan area ber-AC. Keadaan cuaca pada saat melakukan iklim kerja cerah. Pengukuran iklim kerja disesuaikan dengan beban kerja masing-masing tenaga kerja dan dibandingkan dengan nilai ambang batas (NAB) yang sesuai dengan Peraturan Menteri Tenaga Kerja dan Transmigrasi Nomor 13 Tahun 2011.

Beban kerja tenaga kerja sebagian besar adalah beban kerja ringan yang dialami oleh tenaga kerja area non AC. Kemudian untuk beban kerja berat sebagian besar dialami oleh tenaga kerja area dapur. Hal tersebut dikarenakan pada tenaga kerja area dapur pekerjaan yang dilakukan yaitu memasak dalam kondisi berdiri dan mobilitas yang tinggi serta iklim kerja yang tinggi yang mempengaruhi beban kerja tenaga kerja. Sedangkan pada area non AC pekerjaan yang dilakukan adalah menyiapkan makanan di ruang porsi dengan kondisi berdiri dan berjalan, namun juga sesekali duduk, dengan iklim kerja yang tidak terlalu tinggi sehingga tidak terlalu mempengaruhi beban kerja. Lalu untuk area ber-AC tenaga kerja paling banyak melakukan pekerjaan dengan posisi duduk di hadapan komputer, dan dengan iklim kerja rendah sehingga beban kerja yang dialami sebagian besar adalah beban kerja ringan.

Waktu kerja di catering Hikmah Food Surabaya adalah 9 jam dengan lama istirahat, sholat, dan makan 1 jam sehingga jika dihitung waktu kerjanya adalah sebesar $88,8 \%$. Berdasarkan perhitungan tersebut, waktu kerja di catering Hikmah Food Surabaya adalah $75-100 \%$. Menurut Peraturan Menteri Tenaga Kerja dan Transmigrasi Nomor 13 Tahun 2011 pengaturan waktu kerja $75-100 \%$ dengan beban kerja ringan adalah $31^{\circ} \mathrm{C}$ dan beban kerja sedang $28^{\circ} \mathrm{C}$, sedangkan beban kerja berat tidak diperkenankan sama sekali jika pengaturan waktu kerjanya $75-100 \%$ dari waktu istirahatnya.

Hasil pengukuran Indeks Suhu Basah dan Bola (ISBB) di Catering Hikmah Food Surabaya, didapatkan hasil tertinggi pada area dapur, yaitu sebesar $29,6^{\circ} \mathrm{C}$ sedangkan hasil terendah terdapat pada area ber-AC, yaitu $20,3^{\circ} \mathrm{C}$. Selain itu juga diketahui dari hasil penelitian bahwa masih ada tenaga kerja yang berada pada iklim kerja $>$ NAB yang sebagian besar merupakan pekerja pada area dapur. Hal tersebut dikarenakan area dapur merupakan tempat produksi dari catering Hikmah Food di mana terdapat beberapa kompor yang menyala dengan temperatur tinggi untuk proses memasak makanan sehingga aliran panas mengalir ke seluruh area dapur. Sedangkan area ber-AC mempunyai ISBB lebih rendah karena area tersebut merupakan ruangan yang tertutup rapat dan terpasang Air Conditioner (AC) sehingga udara panas dari luar ruangan tidak bisa masuk ke dalam ruangan.

Hasil pengukuran iklim harus disesuaikan dengan beban kerja dan pengaturan waktu kerja dan istirahat masing-masing tenaga kerja selama 1 hari atau 8 jam kerja. Berdasarkan hasil tersebut dapat diketahui bahwa sebagian besar tenaga kerja bekerja pada iklim kerja di bawah NAB. Namun masih ada beberapa tenaga kerja yang bekerja pada area dengan iklim kerja yang melebihi NAB. Hal tersebut menunjukkan bahwa masih ada beberapa tenaga kerja yang bekerja di area iklim kerja panas.

Panas dari lingkungan kerja secara nyata dapat menambah beban panas pada tubuh dan menentukan kecepatan (kemampuan) tubuh dalam melepaskan panas ke udara lingkungan tempat kerja. Selain itu lingkungan kerja yang panas dan lembab akan menurunkan produktivitas kerja yang juga akan membawa dampak negatif terhadap keselamatan dan kesehatan kerja (Soeripto, 2008). Sesuai dengan pendapat Ardyanto (2005) bahwa lingkungan kerja yang panas umumnya lebih banyak menimbulkan permasalahan dibandingkan lingkungan kerja dingin. Hal ini terjadi karena pada umumnya manusia lebih mudah melindungi dirinya dari pengaruh suhu udara yang rendah dari pada suhu udara yang tinggi. Suhu tinggi atau suhu yang panas mengurangi kelincahan, memperpanjang waktu reaksi, dan memperlambat waktu pengambilan keputusan, mengganggu kecermatan kerja otak, mengganggu saraf perasa dan motoris, serta memudahkan emosi untuk dirangsang (Suma'mur, 2009).

Sebagai upaya preventif terhadap penyakit atau gangguan kesehatan akibat lingkungan kerja bersuhu tinggi, yang paling penting adalah aklimatisasi pada lingkungan. Di ruang bekerja suhu tinggi harus tersedia cukup air minum dan juga tablet garam dapur (Suma'mur, 2009). Tenaga kerja dianjurkan untuk minum satu gelas air (150-200 ml) setiap 15-20 menit untuk mencegah terjadinya dehidrasi karena iklim kerja yang tinggi. Lingkungan kerja panas atau jenis pekerjaan berat membutuhkan minum 2,8 liter/hari (Zamsiar, 2015). Kemudian pakaian kerja untuk lingkungan tempat kerja panas 
sebaiknya dari bahan yang mudah menyerap keringat seperti bahan yang terbuat dari katun, sehingga penguapan mudah terjadi (Soeripto, 2008).

Pemasangan ventilasi umum dapat dilakukan pada perusahaan dengan iklim kerja yang tinggi. Sesuai pendapat Anizar (2009), bahwa menerapkan pemasangan exhaust fan sebagai upaya pengendalian lingkungan kerja. Hal ini dimaksud untuk meminimalisasi dampak paparan yang diterima pekerja dari pencemar udara di ruang pabrik. Hal tersebut dipertegas oleh Ardyanto (2005), bahwa pengadaan ventilasi umum diharapkan panas yang menyebar secara radiasi, konduksi, dan konveksi ke seluruh ruang kerja dapat mengalir keluar di mana suhu udaranya lebih rendah. Selain itu juga pemasangan fan dengan tujuan mengalirkan panas secara konveksi ke tempat suhu udara yang lebih rendah. Sehingga dalam hal ini perusahaan dianjurkan untuk memasang ventilasi sistem dorong tarik dengan kecepatan fan sebagai pendorong udara panas $1 \mathrm{~m} / \mathrm{s}$ dan exhaust fan sebagai penarik udara panas dari lingkungan kerja keluar lingkungan dengan suhu yang lebih rendah.

\section{Kelelahan Kerja}

Hasil penelitian pada 43 responden di Catering Hikmah Food Surabaya menunjukkan bahwa semua responden memiliki risiko mengalami kelelahan kerja. Sebagian besar responden mengalami kelelahan sedang. Namun juga terdapat beberapa responden yang mengalami kelelahan kerja tinggi.

Berdasarkan hasil penelitian dapat diketahui pula bahwa tingkat kelelahan kerja rendah paling banyak dialami pada area ber-AC. Untuk kelelahan kerja sedang sebagian besar dialami oleh tenaga kerja pada area non AC. Sedangkan tingkat kelelahan kerja tinggi sebagian besar berada pada area dapur. Pada area ber-AC tidak terdapat tenaga kerja yang mengalami kelelahan tinggi disebabkan karena tekanan panas pada area ber-AC lebih rendah daripada area dapur dan area non AC. Hal tesebut sesuai dengan penelitian Nugroho (2013), yang mengatakan bahwa semakin tinggi tingkat iklim kerja panas semakin tinggi juga tingkat kelelahan kerjanya.

Menurut Suma'mur (2009), bahwa hampir setiap hari kelelahan kerja selalu dikeluhkan oleh para pekerja pada tiap unit kerja, namun lelah merupakan suatu perasaan yang mempunyai arti tersendiri dan sifatnya subjektif bagi setiap orang. Kelelahan subjektif akan mengakibatkan kecelakaan kerja, kerusakan pada alat kerja karena sikap kerja yang salah hingga terjadinya kematian (Fatigue Management for The Australian Industry, 2012). Menurut Tarwaka (2004) kelelahan ringan pada klasifikasi kelelahan kerja bisa dianggap sebagai keadaan normal atau tidak lelah, karena dalam klasifikasi kelelahan, kelelahan rendah belum diperlukan adanya tindakan perbaikan karena kelelahan biasanya hanya bersifat sementara dan dapat pulih kembali setelah diberikan istirahat dan energi secukupnya. Tetapi untuk kelelahan tinggi, diperlukan waktu yang lama untuk mengadakan pemulihan kembali dan ada kalanya bahkan diperlukan obat-obatan untuk memulihkan kondisi agar dapat fit kembali.

Pengendalian kelelahan kerja dapat dilakukan dengan beberapa tindakan oleh perusahaan. Setyawati (2010), mengemukakan bahwa waktu kerja yang berjam-jam harus diselingi oleh istirahat yang cukup untuk makan dan keperluan khusus lain. Disarankan pula agar kegiatan yang menegangkan dan beban kerja yang berat tidak terlalu lama. Lalu juga dibutuhkan pembinaan mental para pekerja di perusahaan secara teratur maupun berkala dan khusus perlu dilaksanakan dalam rangka stabilitas pekerja, dan harus ditangani secara baik di lokasi kerja. Selain itu juga adanya fasilitas rekreasi, waktu rekreasi, dan istirahat direncanakan secara baik dan berkesinambungan, serta cuti dan liburan diberikan kepada pekerja dan dilaksanakan sebaik-baiknya.

\section{Hubungan Antara Status Gizi dengan Kelelahan Kerja}

Pada penelitian ini diketahui bahwa sebagian besar responden dengan status gizi normal mengalami kelelahan kerja kategori sedang. Berdasarkan hasil analisa uji statistik dengan menggunakan uji korelasi spearman menunjukkan bahwa tidak ada hubungan antara status gizi dengan kelelahan kerja. Hal tersebut disebabkan sebagian besar tenaga kerja yang mempunyai status gizi gemuk mengalami kelelahan kerja rendah dan sebagian besar tenaga kerja dengan status gizi normal mengalami kelelahan kerja sedang, yang artinya status gizi tidak menjadi penyebab dari kelelahan kerja seseorang.

Hasil tersebut bertentangan dengan penelitian yang dilakukan oleh Oentoro (2004), mengenai pengaruh status gizi terhadap kelelahan seseorang yang menunjukkan bahwa secara klinis terdapat hubungan antara status gizi seseorang dengan performa tubuh secara keseluruhan. 
Perbedaan hasil penelitian tersebut dapat dipengaruhi berbagai faktor, diantaranya faktor iklim kerja dan faktor karakteristik individu tenaga kerja, seperti faktor usia dan masa kerja yang sudah tergolong lama. Berdasarkan penelitian ditemukan bahwa beban kerja dari tenaga kerja berstatus gizi gemuk rata-rata dikategorikan dalam beban kerja ringan, sehingga tenaga kerja tersebut mengalami kelelahan kerja kategori rendah. Selain itu, juga ditemukan dalam penelitian bahwa tenaga kerja berstatus gizi gemuk bekerja pada area iklim kerja $\leq$ NAB di mana area kerja tersebut dapat meminimalisir timbulnya kelelahan sehingga tenaga kerja mengalami kelelahan kerja kategori rendah. Faktor lain yang mempengaruhi adalah karakteristik individu, yaitu usia yang mempengaruhi kelelahan kerja. Berdasarkan hasil penelitian menunjukkan bahwa sebagian besar tenaga kerja dengan status gizi gemuk mempunyai usia sekitar 20-30 tahun, sehingga tenaga kerja tersebut mengalami kelelahan kerja kategori rendah. Sesuai pendapat Oentoro (2004), yang menyatakan bahwa tenaga kerja yang berusia 40-50 tahun akan lebih cepat menderita kelelahan dibandingkan dengan tenaga kerja yang relatif lebih muda.

Beberapa pengaruh tersebut sesuai dalam pernyataan Tarwaka (2004), bahwasanya faktorfaktor yang menyebabkan terjadinya kelelahan adalah kesegaran jasmani, kebiasaan merokok, masalah psikologis, status kesehatan, jenis kelamin, status gizi, waktu kerja, beban kerja, usia, dan masalah lingkungan kerja. Sehingga dalam hal ini banyak faktor yang menyebabkan kelelahan kerja tidak hanya status gizi namun juga dari faktor beban kerja, lingkungan kerja, dan usia tenaga kerja.

Selain itu terdapat beberapa penelitian yang menunjukkan bahwa tidak ada hubungan antara status gizi dan kelelahan kerja, yaitu pada penelitian yang dilakukan oleh Atiqoh, dkk (2014), yang menunjukkan bahwa tidak ada hubungan antara status gizi dengan kelelahan kerja. Lalu pada penelitian Dewi (2013), mengenai hubungan antara asupan makan, status gizi, dan kelelahan kerja terhadap produktivitas kerja menunjukkan bahwa tidak ada hubungan status gizi dengan kelelahan kerja. Selain itu juga Melati (2013), juga menunjukkan bahwa tidak ada hubungan antara status gizi dengan kelelahan kerja.

Kemudian juga pada penelitian $\operatorname{Irma(2014),}$ mengenai faktor yang berhubungan dengan kelelahan kerja yang menunjukkan bahwa variabel status gizi tidak berhubungan dengan kelelahan kerja. Dengan demikian, penelitian tersebut mendukung hasil penelitian pada tenaga kerja Catering Hikmah Food Surabaya, yaitu tidak ada hubungan antara status gizi dengan kelelahan kerja.

\section{Hubungan Antara Iklim Kerja dengan Kelelahan Kerja}

Pada penelitian ini diketahui bahwa seluruh tenaga kerja pada kondisi ISBB yang melebihi nilai ambang batasnya mengalami kelelahan kerja tinggi. Menurut Permenakertrans (2011), ISBB maksimal untuk waktu kerja $75-100 \%$ pada beban kerja ringan adalah $31^{\circ} \mathrm{C}$ dan $28^{\circ} \mathrm{C}$ untuk beban kerja sedang. Sedangkan beban kerja berat tidak ditolerir sama sekali untuk waktu kerja $75-100 \%$ sehingga tidak memiliki nilai ambang batas ISBB.

Hasil analisa uji statistik dengan menggunakan uji korelasi spearman menunjukkan bahwa ada hubungan antara iklim kerja dengan kelelahan kerja. Hubungan tersebut mempunyai kekuatan hubungan yang sedang dan hubungan yang searah antara iklim kerja dengan kelelahan kerja, yaitu jika semakin tinggi iklim kerja maka kelelahan akan semakin meningkat. Tenaga kerja bekerja dengan iklim kerja lebih dari NAB dikarenakan sebagian pekerjaan di Catering Hikmah Food Surabaya dilakukan pada kondisi berdiri sehingga dapat meningkatkan beban kerja dan mempengaruhi kondisi iklim kerja maksimal yang dapat diterimanya.

Pemaparan suhu lingkungan panas yang berlebihan dapat menyebabkan gangguan perilaku dan performasi kerja seperti terjadinya kelelahan, sering melakukan istirahat curian, dan dapat menyebabkan heat exhaustion. Hal tersebut jika tidak segera dikendalikan akan berpengaruh terhadap kenyamanan tenaga kerja dan gangguan kesehatan sehingga dapat menambah beban kerja tenaga kerja, mempercepat munculnya kelelahan kerja serta dapat menurunkan produktivitas kerja (Tarwaka, 2004). Hal ini dipertegas oleh Soeripto (2008) yang menyatakan bahwa kiranya bukanlah suatu kejutan apabila di dalam lingkungan kerja yang panas, frekuensi kecelakaan menjadi meningkat, hal ini disebabkan oleh penampilan fisik dan kepekaan mental yang menurun karena pengaruh dari panas.

Namun terdapat beberapa tenaga kerja yang mengalami kelelahan kerja kategori sedang dan rendah. Hal tersebut terjadi apabila tenaga kerja sudah teraklimatisasi dengan kondisi panas lingkungan kerja serta memiliki kondisi kesehatan yang prima. Aklimatisasi berarti tenaga kerja sudah beradaptasi dan terbiasa dengan panas iklim kerja. 
Hal ini sesuai dengan pernyataan Grantham (1992) dalam Tarwaka (2010), yang menyebutkan bahwa pekerjaan dan lingkungan panas memerlukan aklimatisasi untuk mengurangi reaksi tubuh terhadap panas (heat strain).

Penelitian ini didukung oleh hasil dari penelitian Krisanti (2011), yang menghasilkan bahwa ada hubungan antara tekanan panas dengan kelelahan kerja pada tenaga kerja. Dengan demikian penelitian tersebut mendukung hasil penelitian pada tenaga kerja Catering Hikmah Food Surabaya, yaitu adanya hubungan yang bermakna antara iklim kerja dengan kelelahan kerja.

\section{SIMPULAN}

Berdasarkan hasil penelitian yang dilakukan mengenai faktor yang mempengaruhi kelelahan kerja pada 43 tenaga kerja di Catering Hikmah Food Surabaya dapat ditarik kesimpulan bahwa status gizi tenaga kerja sebagian besar adalah berstatus gizi gemuk $(48,8 \%)$. Status gizi gemuk sebagian besar terdapat pada tenaga kerja area non AC $(47,6 \%)$. Iklim kerja hasil pengukuran Indeks Suhu Basah Bola (ISBB) paling tinggi terdapat pada area dapur yaitu $29,6^{\circ} \mathrm{C}$ dan paling rendah terdapat pada area ber-AC yaitu $20,3^{\circ} \mathrm{C}$. Tenaga kerja dengan iklim kerja $>\mathrm{NAB}$ paling banyak terdapat pada area dapur $(85,7 \%)$. Kelelahan kerja yang dialami oleh tenaga kerja adalah kelelahan sedang $(55,8 \%)$. Kelelahan kerja sedang paling banyak dialami oleh tenaga kerja pada area non $\mathrm{AC}(75 \%)$. Kelelahan kerja tinggi paling banyak dialami oleh tenaga kerja area dapur (75\%). Tidak ada hubungan antara status gizi dengan kelelahan kerja. Namun ada hubungan antara iklim kerja dengan kelelahan kerja dengan tingkat hubungan sedang.

\section{DAFTAR PUSTAKA}

Anizar.2009. Teknik Keselamatan dan Kesehatan Kerja di Industri. Yogyakarta: Graha Ilmu.

Ardyanto, D.2005. Potret Iklim Kerja dan Upaya Pengendalian Lingkungan pada Perusahaan Peleburan Baja di Sidoarjo. Jurnal Kesehatan Lingkungan Vol. 1, No. 2. Surabaya: Fakultas Kesehatan Masyarakat Universitas Airlangga.

Atiqoh, J. 2014. Faktor-faktor yang Berhubungan dengan Kelelahan Kerja pada Pekerja Konveksi Bagian Penjahitan di CV. Aneka Garment Gunungpati Semarang. Skripsi. Semarang: Universitas Diponegoro.
Budiono, A.M.2003. Bunga Rampai Hiperkes dan Keselamatan Kerja: Hygiene Perusahaan, Ergonomi, Kesehatan Kerja, dan Keselamatan Kerja. Semarang: Badan Penerbit Universitas Diponegoro.

Centers for Disease Control and Prevention (CDC).2011. Healthy Weight -It's not a diet, It's a Lifestyle. District of Columbia.

Dewi, M.M. 2013. Hubungan Antara Asupan Makan, Status Gizi, dan Kelelahan Kerja Terhadap Produktivitas Kerja pada Pekerja Pabrik PT. Tigaraksa Satria Tbk. Yogyakarta. Skripsi. Yogyakarta: Universitas Gajah Mada.

Irma, M.R.2014. Faktor yang Berhubungan dengan Kelelahan Kerja pada Unit Produksi Paving Block CV. Sumber Galian Kecamatan Biringkanaya Kota Makassar. Skripsi. Makassar: Universitas Hassanudin.

Kementerian Tenaga Kerja dan Transmigrasi. 2011. Peraturan Menteri Tenaga Kerja dan Transmigrasi Nomor PER.13/MEN/X/2011 Tahun 2011 Tentang Nilai Ambang Batas Faktor Fisika dan Faktor Kimia di Tempat Kerja. Jakarta: Bidang Ketenagakerjaan dan Ketransmigrasian Kementrian Tenaga Kerja dan Transmigrasi RI.

Krisanti, R.D. 2011. Hubungan Antara Tekanan Panas dengan Kelelahan Kerja pada Tenaga Kerja Bagian Produksi di CV. Rakabu Furniture Surakarta. Skripsi. Surakarta: Universitas Sebelas Maret Surakarta.

Melati, S.2013. Hubungan Antara Usia, Masa Kerja, dan Status Gizi dengan Kelelahan Kerja pada Pekerja Mebel di CV. Mercusuar dan CV. Mariska Desa Lielem Kecamatan Sonder Kabupaten Minahasa. Skripsi. Manado: Universitas Sam Ratulangi.

Nugroho, A. 2013. Pengaruh Iklim Kerja Panas Terhadap Kelelahan Tenaga Kerja di Bagian Peleburan Logam Koperasi Batur Jaya Ceper Klaten. Artikel Publikasi Ilmiah. Surakarta: Universitas Muhammadiyah Surakarta.

Oentoro, S. 2004. Kampanye Atasi Kelelahan Mental dan Fisik. Jakarta: UI Press.

Ramayanti, R. 2015. Hubungan Status Gizi dan Beban Kerja terhadap Kelelahan Kerja (Studi pada Tenaga Kerja PT. Hikmah Sejahtera Bagian Catering Hikmah Food Surabaya). Skripsi. Surabaya: Universitas Airlangga.

Setyawati, Lientje. 2010. Selintas Tentang Kelelahan Kerja. Yogyakarta: Amara Books. 
Soeripto. 2008., Hygiene Industri. Jakarta: Balai Penerbit Fakultas Kedokteran Universitas Indonesia.

Suma'mur P.K. 2009. Higiene Perusahaan dan Kesehatan Kerja. Jakarta: Sagung Seto,

Supariasa, I.D.N.2002. Penilaian Status Gizi. Jakarta: Penerbit Buku Kedokteran EGC.

Tarwaka. 2004. Ergonomi untuk Keselamatan, Kesehatan Kerja, dan Produktivitas. Surakarta: Uniba Press.

Tarwaka. 2010. Ergonomi Industri. Surakarta: Harapan Press.
Wahyuni, A. 2009. Faktor yang Berhubungan Terhadap Kelelahan CSSD Laundry Rumah Sakit di Kota Makassar. Tesis. Makassar: Universitas Hasanuddin.

World Health Organization (WHO).2000. Klasifikasi Berat Badan Berdasarkan BMI pada Penduduk Asia Dewasa.

Zamsiar, Nusye. 2015. Pedoman Kebutuhan Cairan Bagi Pekerja agar Tetap Sehat dan Produktif. Jakarta: PERDOKI. 